\title{
A reassessment of primary thyroid lymphoma: high-grade MALT-type lymphoma as a distinct subtype of diffuse large B-cell lymphoma
}

\author{
M Skacel, C W Ross $^{1}$ \& E D Hsi \\ Cleveland Clinic Foundation, Cleveland, OH, and ${ }^{1}$ University of Michigan, Ann Arbor, MI, USA
}

Date of submission 27 August 1999

Accepted for publication 22 December 1999

Skacel M, Ross CW \& Hsi ED

(2000) Histopathology 37, 10-18

\section{A reassessment of primary thyroid lymphoma: high-grade MALT-type lymphoma as a distinct subtype of diffuse large B-cell lymphoma}

Aims: Primary lymphoma of the thyroid gland (PTL) is a relatively rare disease. During an 18-year period, 53 cases of primary non-Hodgkin's lymphoma involving this extranodal site were seen at our institutions. The aims of this study were to evaluate the spectrum of PTLs using current lymphoma classification concepts and immunocytochemical markers, determine whether features of MALT-type lymphoma were evident in PTL, and if there was any clinical significance of such a finding. Methods and results: The cases were retrospectively studied clinically, histologically and immunohistochemically. The tumours were classified according to the Revised European-American Lymphoma Classification of lymphoid malignancies (REAL classification). Thirty-eight patients were females, 15 were males and mean age at diagnosis was 66.3 years (range 38-90). Three cases were low-grade marginal zone lymphomas (low-grade MALT-type lymphomas). There were 45 diffuse large B-cell lymphomas (DLBCL) of which there were 27 DLBCL-NOS and 18 high-grade MALT-type lymphomas. Within the diffuse large B-cell lymphoma (DLBCL) category, cases were subdivided into those without (DLBCL-NOS) and those with features of 'highgrade' MALT-type lymphoma based on presence of a low-grade component or large cell lymphoepithelial lesions (HG MALT-type lymphoma). In addition there were three follicle centre lymphomas, one anaplastic large cell lymphoma and one peripheral T-cell lymphoma. Twenty cases were stage $\mathrm{I}_{\mathrm{E}}, 18$ stage $\mathrm{II}_{\mathrm{E}}$, and four stage IV. All patients with low-grade MALT-type lymphoma are alive without disease. The 5-year survivals for DLBCL-NOS and HG MALT-type lymphoma were $75 \%$ and $25 \%$, respectively. Univariate analysis (log rank) among the DLBCLs showed stage $(P<0.001)$ and subtype $(P=0.005)$ were associated with survival. Stage was associated with type of DLBCL, $65 \%$ of DLBCL-NOS being stage $\mathrm{I}_{\mathrm{E}}$ compared to $20 \%$ of $\mathrm{HG}$ MALT-type lymphomas.

Conclusions: We conclude that primary thyroid lymphomas occur most commonly in elderly women and are frequently present in clinical stage $\mathrm{I}_{\mathrm{E}}$ and $\mathrm{II}_{\mathrm{E}}$. Low-grade MALT-type lymphomas are relatively uncommon but appear to have a favourable prognosis. DLBCL is the most common lymphoma and features of MALT can be seen in over one-third of cases. As a group, HG MALTtype lymphomas had a worse outcome than DLBCLNOS, primarily due to higher clinical stage at diagnosis. These two subtypes of DLBCL appear to be distinct clinical and histological entities.

Keywords: lymphoepithelial lesion, MALT-type lymphoma, mucosa-associated lymphoid tissue (MALT), primary thyroid lymphoma

Address for correspondence: Dr ED Hsi, Department of Clinical Pathology, L-11, Cleveland Clinic Foundation, 9500 Euclid Avenue, Cleveland, OH 44195, USA. e-mail: hsie@ccf.org

\section{Introduction}

Primary thyroid lymphoma (PTL) affects predominantly elderly patients, the majority of them women over 60 years of age. The condition is rare, accounting for less 
than $5 \%$ of all thyroid malignancies ${ }^{1}$ and less than $2 \%$ of extranodal lymphomas. ${ }^{2}$ Thus they are seen infrequently by most pathologists and can be confused with a wide variety of entities, including benign disorders such as Hashimoto's thyroiditis at one end of the spectrum and undifferentiated carcinomas at the other end.

In general, PTLs are most commonly high-grade (large cell) lymphomas ${ }^{3-6}$ although occasional series show a predominance of low-grade lymphomas. ${ }^{7}$ Relatively few large series of primary thyroid lymphoma have been published and varying terminologies have been used over the years. Most reports of primary thyroid lymphoma were published prior to the publication of the REAL classification and the concept of lowgrade B-cell lymphomas of mucosa-associated lymphoid tissue (MALT) type. ${ }^{2-17}$ In the recent literature only two studies focused on the clinical significance of histological grade and histopathological features of MALT for prognosis of these neoplasms. ${ }^{18,19}$ One found morphological subtype did not correlate significantly with survival in a series of 50 cases. ${ }^{19}$ In the other study, the authors analysed 45 cases and reported a favourable prognosis for thyroid lymphomas with features of MALT even within high-grade lymphomas. ${ }^{18}$ We report our retrospective analysis of 53 patients with primary malignant lymphoma of the thyroid gland using modern histopathological classification. The relationship between overall survival, histological grade and the presence or absence of MALT origin was investigated.

\section{Materials and methods}

CASE SELECTION

The cases were retrieved from the pathology files of the Cleveland Clinic Foundation, Cleveland, Ohio and University of Michigan, Ann Arbor, Michigan. A total of 53 cases during the 18-year period 1980-98 was available for study (19 from the University of Michigan and 34 from the Cleveland Clinic Foundation). Thirtyfive cases were diagnosed on either excisional biopsy, subtotal or total thyroidectomy. Eighteen patients underwent a needle biopsy. Paraffin blocks were available from all cases and the sections were stained with haematoxylin and eosin.

The clinical records of the patients were analysed with respect to symptoms, stage, treatment and survival. Cases were included in the study when primary symptoms and the reason for seeking medical advice were associated with disease of the thyroid gland. ${ }^{20}$ For clinical staging the modified Ann Arbor classification was used..$^{21,22}$ All of our stage $\mathrm{II}_{\mathrm{E}}$ cases except one would belong to the $\mathrm{II}_{\mathrm{E} 1}$ stage according to Musshoff (the lymph node involvement limited to regional nodes). ${ }^{21}$ Therefore we did not use the subclassification of the stage $\mathrm{II}_{\mathrm{E}}$ lymphomas in our study.

\section{CLASSIFICATION BY HISTOLOGICAL TYPE}

The lymphomas were reviewed and classified according to the REAL classification. ${ }^{23}$ The type of specimen (excision or needle biopsy) was noted. Among the DLBCLs, cases were further subdivided into DLBCL-NOS (where there was no evidence of MALT origin) or HG MALT-type lymphoma. In the latter, the diagnosis was based on presence of a low-grade MALT component or large cell lymphoepithelial lesions (lymphoepithelial lesions composed of large lymphoma cells).

\section{IMMUNOHISTOCHEMISTRY}

Formalin or B5-fixed, paraffin-embedded tissues were stained with the following antibodies: AE1/AE3 (cytokeratins, titre $1: 300$, Boehringer Mannheim, Indianapolis, IN), L26 (CD20, titre 1:500, DAKO Corporation, Carpinteria CA), Leu22 (CD43, 1:200, Becton Dickinson, San Jose, CA), peroxidase-conjugated rabbit polyclonal anti-kappa $(1: 80$, DAKO) and peroxidaseconjugated rabbit polyclonal anti-lambda $(1: 20$, DAKO). Two cases of follicle centre lymphoma were also stained with CD10 (1:5, Novocastra Laboratories, Newcastle, UK) and bcl-2 (neat, Ventana Medical System, Tucson, AZ). The one case of peripheral T-cell lymphoma was also stained with UCHL-1 (CD45RO, $1: 50$, Zymed Laboratories, San Francisco, CA). Staining was performed using an automated stainer (Ventana Medical System, Tucson, AZ), with microwave antigen retrieval for CD20, CD43, CD10 and bcl-2 (10 mm citrate, pH 6.0). The peroxidase-conjugated antibodies were detected by incubating the deparaffinized steam-pretreated tissues with the following reagents (room temperature): 3\% hydrogen peroxide/ methanol for $20 \mathrm{~min}$, suppressor goat serum $(1: 20)$ for $10 \mathrm{~min}$, primary antiserum for $1 \mathrm{~h}$, and $0.4 \mathrm{~g} / \mathrm{l} \mathrm{DAB}$ with $60 \mathrm{mg} / \mathrm{l}$ hydrogen peroxide in phosphate-buffered saline ( $\mathrm{pH} 7.15$ ) for $10 \mathrm{~min}$

Not every case was evaluable for each marker because of a lack of sufficient amount of tissue in the paraffin blocks. In two cases of DLBCL kappa and lambda stains were not performed and in one LG MALTtype lymphoma cytokeratin and CD43 could not be performed. In one HG MALT-type lymphoma, eight DLBCL-NOS and one FCL, only an immunostain for CD 20 was available. 
CLINICAL FOLLOW-UP

The clinical follow-up was obtained from patient records and communication with referring physicians. The clinical stage was based on available information in the patient record and matched the recorded clinical stage in all cases.

\section{STATISTICAL ANALYSIS}

Kaplan-Meier survival curves were calculated using death from the disease as the clinical endpoint for disease-specific survival. Curves were compared by the log-rank test. The chi-square was used in univariate analysis of nominal data. All analyses were performed using Statistica statistic software (Statsoft, Tulsa, OK).

The follicle centre lymphomas, anaplastic large cell lymphoma and peripheral T-cell lymphoma were not included in the statistical analysis, since they represented only rare histological types encountered in the thyroid gland. Also the low-grade MALT-type lymphomas were too few to be analysed.

A separate survival analysis of DLBCL-NOS and HG MALT-type lymphomas was also performed after exclusion of all cases diagnosed by needle biopsy. This was done in an effort to reduce bias based on small tissue sample size.

\section{Results}

CLINICAL

Fifty-three cases of thyroid lymphomas from 38 women and 15 men were studied (male: female ratio $1: 2.5$ ).
These 53 cases included three low-grade MALT-type lymphomas, 27 DLBCL-NOS, 18 HG MALT-type lymphomas, three follicle centre lymphomas, one anaplastic large cell lymphoma and one peripheral T-cell lymphoma. The presenting symptoms were known in 52 patients. A neck mass was observed in all 52 cases at admission, 19 patients (37\%) also complained of dysphagia, nine $(17 \%)$ had signs of tracheal compression and seven patients (13\%) also presented with hoarseness. The age of the patients ranged from 38 to 90 years (mean 66.3 years). Clinical stage of the disease was known in 42 patients.

Patient distribution according to stage is detailed in Table 1. For 11 patients, the stages were unknown. 20 cases were stage $\mathrm{I}_{\mathrm{E}}, 18$ stage $\mathrm{II}_{\mathrm{E}}$, and four stage IV. All low-grade MALT-type lymphomas were stage $\mathrm{I}_{\mathrm{E}}$. Within the high-grade MALT-type lymphoma category, three cases $(20 \%)$ were stage $\mathrm{I}_{\mathrm{E}}, 10$ cases $(67 \%)$ were stage $\mathrm{II}_{\mathrm{E}}$ and two $(13 \%)$ were stage IV. Within the DLBCL-NOS category, 13 cases $(65 \%)$ were stage $\mathrm{I}_{\mathrm{E}}, 6(30 \%)$ stage $\mathrm{II}_{\mathrm{E}}$ and one case $(5 \%)$ was stage IV.

HISTOPATHOLOGY AND IMMUNOPHENOTYPING

Extranodal marginal zone B-cell lymphoma (low-grade MALT-type lymphoma)

Excisional biopsies were available for review for all three patients with low-grade MALT-type lymphomas. All cases were characterized by a dense infiltrate of marginal zone cells. Cells were small-to-intermediate

\begin{tabular}{lllc}
\hline Subtype & Number & Stage* & Number \\
\hline Low-grade MALT-type lymphoma & 3 & $\mathrm{I}_{\mathrm{E}}$ & 3 \\
\hline High-grade MALT-type lymphoma & 18 & $\mathrm{I}_{\mathrm{E}}$ & 3 \\
& & $\mathrm{I} \mathrm{I}_{\mathrm{E}}$ & 10 \\
& 27 & $\mathrm{IV}$ & 2 \\
\hline DLBCL-NOS & & $\mathrm{I}_{\mathrm{E}}$ & 13 \\
& & $\mathrm{II}_{\mathrm{E}}$ & 6 \\
\hline Follicle centre lymphoma & 3 & $\mathrm{IV}$ & 1 \\
\hline T-cell anaplastic large cell lymphoma & 1 & $\mathrm{I}_{\mathrm{E}}$ & 1 \\
\hline Peripheral T-cell lymphoma & 1 & $\mathrm{II}_{\mathrm{E}}$ & 1 \\
\hline
\end{tabular}

Table 1. Summary of stages

*Stage information not available in seven cases of DLBCL, three cases of high-grade MALT lymphoma and one case of follicle centre lymphoma. 


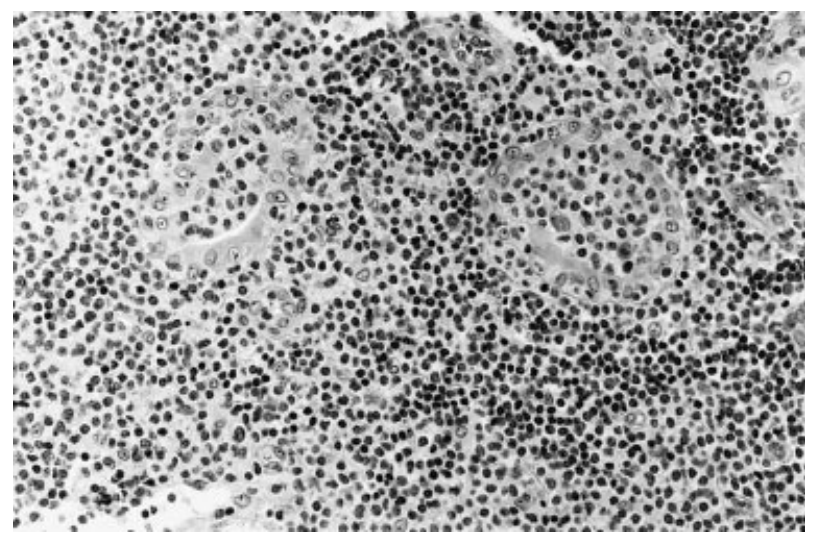

Figure 1. Low-grade MALT-type lymphoma. Lymphoepithelial lesions are distended and filled with marginal zone cells.

in size with irregular (but not cleaved) nuclei and clear cytoplasm. Scattered larger cells were occasionally present. Large lymphoepithelial lesions (LELs) distended and 'stuffed' with marginal zone cells were present in all cases (Figure 1). Lymphocytic thyroiditis was seen in adjacent thyroid tissue in all three cases.
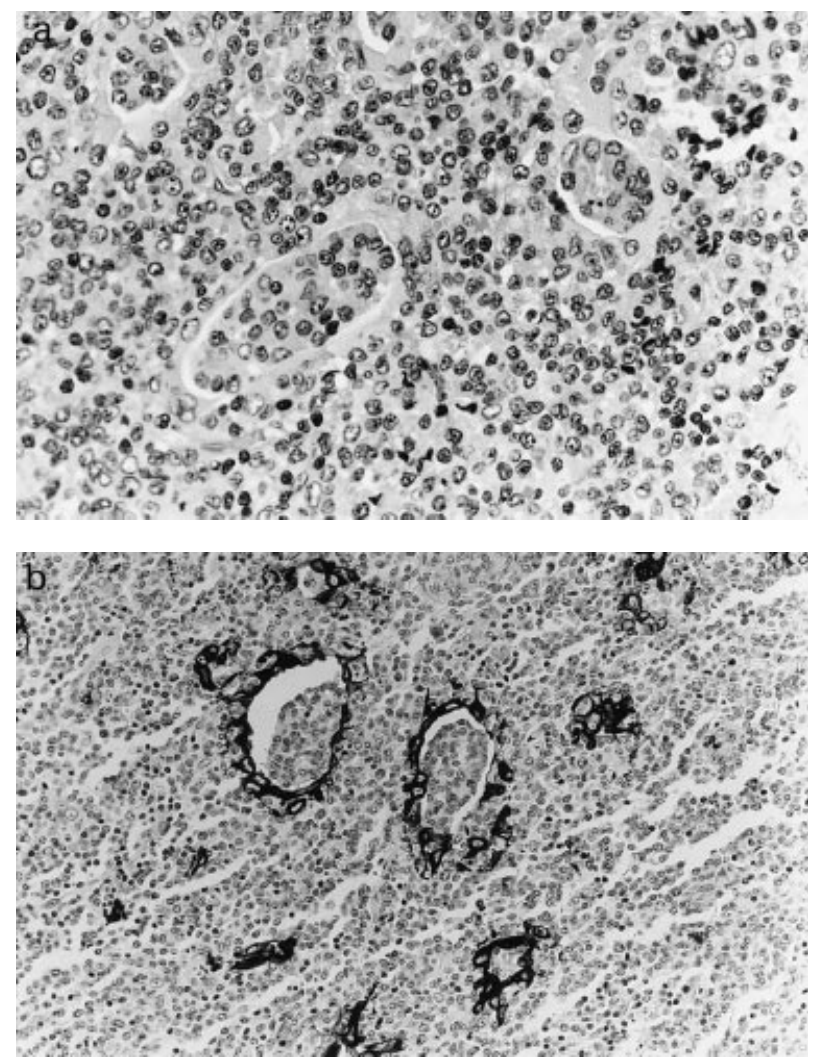

Figure 2. a, High-grade MALT-type lymphoma. Lymphoepithelial lesions are composed of large cells with vesicular chromatin and small nucleoli. b, High-grade MALT-type lymphoma. Cytokeratin stain highlights the lymphoepithelial lesions filled with large cells.
Immunohistochemistry showed CD20 expression on neoplastic cells, including those within LELs, in all cases. All three cases contained polytypic plasma cells.

\section{Diffuse large B-cell lymphoma-high-grade MALT-type lymphoma}

Sixteen patients were found to have diffuse large B-cell lymphoma without a recognizable low-grade component and were classified as high-grade MALT-type lymphomas by virtue of LELs composed of large cells. These cells had vesicular chromatin and multiple small nucleoli resembling centroblasts (Figure 2a). Eight cases showed lymphocytic thyroiditis in adjacent thyroid tissue. All specimens available were excisional biopsies. All cases expressed CD20 in neoplastic cells. CD43 coexpression was seen in three cases. No light chain restriction was seen in plasma cells. Cytokeratin stain highlighted the lymphoepithelial lesions (Figure 2b). In one case, due to the lack of tissue, only a CD20 immunostain was available.

Two cases showed large cell lymphoma in a background of low-grade MALT-type lymphoma. The lowgrade component was recognized by small areas with a diffuse infiltrate of marginal zone cells and the presence of low-grade LELs composed of small lymphocytes. Both cases showed lymphocytic thyroiditis in adjacent thyroid tissue. Tissue available for review was from excisional biopsies in both cases. Neoplastic cells in both cases expressed CD20, whereas coexpression of CD43 was seen in one case. Kappa light chain restriction in plasma cells was seen in both cases.

\section{Diffuse large B-cell lymphoma - NOS}

Twenty-seven cases were classified in this group, where no features of MALT-type lymphoma were seen. Cytologically, these lymphomas were composed predominantly of large, centroblastic cells arranged in sheets, replacing the thyroid follicles without forming any LELs (Figure 3). Lymphocytic thyroiditis was seen in five cases, however, in 15 cases of this group little or no residual thyroid tissue was available for review. Excisional biopsies were available from 11 patients and needle biopsies from 16 patients.

Immunohistochemistry showed CD20 expression in all cases and CD43 coexpression in one case. No light chain restriction was seen by paraffin immunohistochemistry. The cytokeratin stain confirmed the absence of LELs. In 8 cases, due to the lack of tissue, only a CD20 stain was available.

\section{Follicle centre lymphomas}

Three patients were found to have classic architecture of a follicle centre lymphoma, with uniform nodularity and little variation in size and shape of the follicles, a 


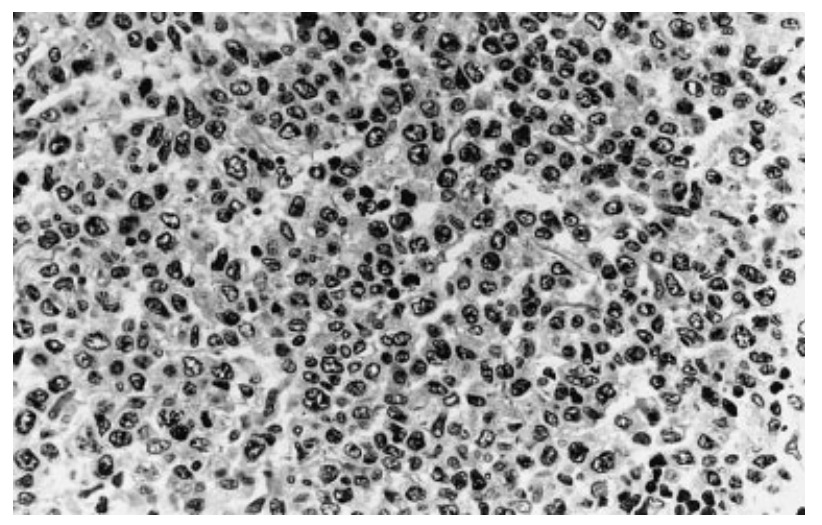

Figure 3. Diffuse large cell lymphoma, NOS. Large, centroblastic cells arranged in sheets replace the follicles without forming any lymphoepithelial lesions.

back-to-back arrangement of follicles, lack of cellular polarization and absence of tingible body macrophages. All three cases were classified as provisional grade 2 follicle centre lymphomas (mixed, small cleaved and large cell). Evidence of lymphocytic thyroiditis was seen in one case. Two specimens were excisional biopsies and one was a needle biopsy.

Neoplastic cells stained with CD20 in all three cases, CD10 and bcl-2 in two cases where there was tissue available for immunostaining, and one of these showed kappa light chain restriction by paraffin immunohistochemistry. In one case, due to the lack of tissue, only a CD20 stain was available.
Anaplastic large cell lymphoma

One case was classified as anaplastic large cell lymphoma, characterized by a proliferation of large lymphoma cells with bizarre, anaplastic cytologic features. An excisional biopsy was available from this patient. The tumour cells expressed CD43, were negative for $\mathrm{CD} 20$, and showed membranous and Golgi immunostaining with anti-CD30.

\section{Peripheral T-cell lymphoma}

In one case a diagnosis of peripheral T-cell lymphoma, unspecified was made based on a relatively homogenous population of small cells with irregularly shaped nuclei, diffusely replacing the thyroid architecture. A needle biopsy was available in this case. The neoplastic cells expressed CD43 and CD45RO but were negative for CD20.

\section{Clinical outcome}

Treatment information was available for 42 patients. Therapeutic approaches included: radiotherapy alone (11 patients); chemotherapy alone (12 patients); chemotherapy and radiotherapy (13 patients); surgery, chemotherapy and radiotherapy (three patients); surgery and radiotherapy (two patients); and surgery and chemotherapy (one patient).

Clinical follow-up was available for 45 patients; the mean follow-up was 46.5 months (range 1-151 months). Overall, 14 patients died of disease, four were alive with disease, and 27 were alive without evidence of disease.

\begin{tabular}{lclc}
\hline Subtype & Number & Patient status* & Number \\
\hline Low-grade MALT-type lymphoma & 3 & ANED & 3 \\
\hline High-grade MALT-type lymphoma & 18 & ANED & 7 \\
& & AWD & 1 \\
\hline DLBCL-NOS & 27 & DOD & 8 \\
\hline Follicle centre lymphoma & & ANED & 16 \\
& & AWD & 2 \\
\hline T-cell anaplastic large cell lymphoma & 3 & DOD & 4 \\
\hline Peripheral T-cell lymphoma & 1 & ANED & 1 \\
\hline
\end{tabular}

Table 2. Summary of clinical outcome

ANED, alive, no evidence of disease; AWD, alive with disease; DOD, dead of disease.

* Patient status unknown in five cases of DLBCL, two cases of high-grade MALT-type lymphoma and one case of follicle centre lymphoma. 
All patients with low-grade MALT-type lymphoma were alive without disease at a mean of 26 months. Eight patients (53\%) with high-grade MALT-type lymphoma died of disease at a mean of nine months from diagnosis. Four patients $(20 \%)$ with DLBCL-NOS died of disease at a mean of 30 months from diagnosis. Clinical follow-up was available in two patients with follicle centre lymphoma. None of them died of disease at a mean of 121 months. The patient with anaplastic large cell lymphoma died of disease at 41 months after diagnosis. The patient with peripheral T-cell lymphoma died of disease one month after diagnosis (see Table 2 for a summary of clinical outcome).

The five-year survivals for DLBCL-NOS and highgrade MALT-type lymphomas were $75 \%$ and $25 \%$, respectively. Among the DLBCLs, Kaplan-Meier curves and log rank analysis showed that clinical stage and histological subtype were highly significant factors in disease-specific survival $(P<0.001$ and $P=0.005$, respectively; Figures 4 and 5). Stage was associated with histological type, $65 \%$ of DLBCL-NOS being stage $\mathrm{I}_{\mathrm{E}}$ compared to $20 \%$ of high-grade MALT-type lymphomas. Age of the patient at the time of diagnosis (lower vs. higher than 65 years) was not significantly associated with survival on univariate analysis.

Diagnosis of all low and high-grade MALT-type lymphomas was based on examination of excisional biopsy or thyroidectomy specimens. Eleven cases of DLBCL-NOS (41\%) were diagnosed on excisional biopsy or thyroidectomy specimens; in the remaining 16 cases (59\%) a needle biopsy was available. To eliminate a potential influence of the type of specimen on our findings, we performed separate survival analysis limited to excisional biopsies and thyroidectomy specimens. This analysis confirmed the significance of both

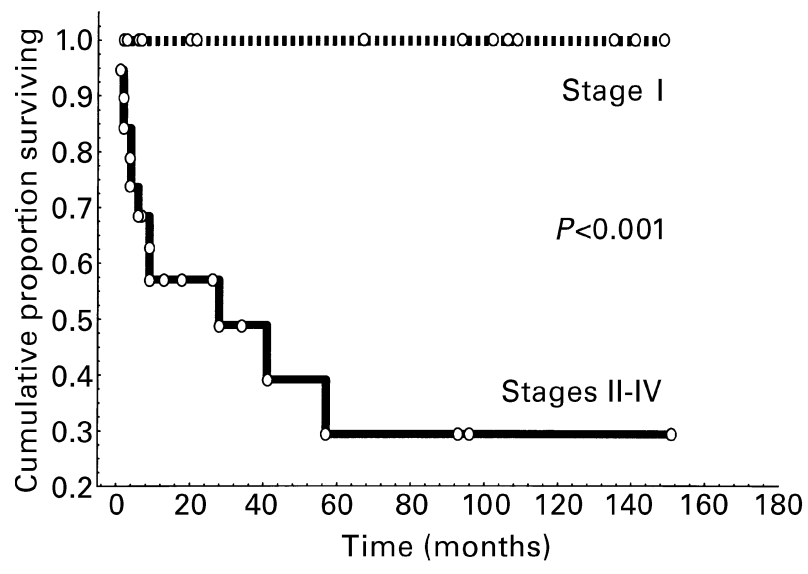

Figure 4. Survival by stage (stage $\mathrm{I}_{\mathrm{E}}$ vs. stages $\mathrm{II}_{\mathrm{E}}-\mathrm{IV}$ ).

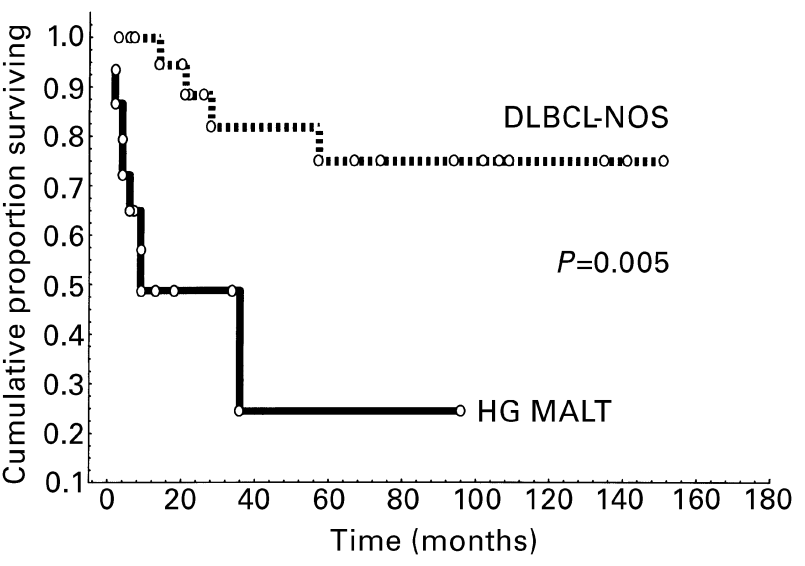

Figure 5. Survival by diagnosis (DLBCL-NOS vs. HG MALT-type lymphoma).

subtype $(P=0.029)$ and stage of the disease $(P=0.02)$ for survival.

As listed above, the mode of therapy varied among cases due to the retrospective nature of the study spanning 20 years. We attempted to analyse the impact of different therapeutic regimens on outcome of highstage patients (stages II-IV) grouped by radiotherapy alone, chemotherapy alone and chemotherapy with radiotherapy. However, we did not find any significant difference in survival (log rank: $P=0.3$ ).

\section{Discussion}

The concept of lymphomas of mucosa-associated lymphoid tissue has been extensively described in gastric lymphomas and has been extended to extranodal lymphomas at many sites, including the thyroid. MALTtype lymphomas can undergo transformation to large cell (high-grade) lymphoma and several studies have recognized the features of MALT in large cell lymphomas at MALT sites, most commonly in the stomach. ${ }^{24-}$ ${ }^{27}$ These studies showed that between $17 \%$ and $68 \%$ of all gastric lymphomas had features of a high-grade MALT-type lymphoma (presence of LELs or a low-grade component). It appears that the presence of a highgrade component in the stomach has prognostic significance. ${ }^{28}$ In contrast to the stomach, there have been very few studies of primary thyroid lymphoma focusing on the presence of histopathological features of MALT, since most series were published prior to the widespread recognition of the histopathological features of MALT.

We retrospectively reviewed a series of 53 primary lymphomas of the thyroid gland, using modern

(C) 2000 Blackwell Science Ltd, Histopathology, 37, 10-18. 
lymphoma classification criteria, to determine their histological spectrum and investigating the significance of MALT features, particularly in high-grade (large cell) lymphomas. The majority ( 45 of 53 , or $85 \%$ ) of cases of primary thyroid lymphomas in our series were diffuse large B-cell lymphomas. This is in agreement with a number of previous studies. ${ }^{4,6,12,16,19}$ In addition, we found features of MALT-type lymphoma in 18 of 45 $(40 \%)$ of DLBCLs. In two cases there was evidence of a concurrent low-grade MALT-type component in the background. In the remaining cases there was no recognizable low-grade component, but lymphoepithelial lesions composed of large lymphoma cells were noted (high-grade LELs). Because LELs are one of the hallmarks of MALT-type lymphomas, ${ }^{6,29}$ we classified these large-cell lymphomas as high-grade MALT lymphomas. In 27 of 45 (60\%) DLBCLs, no features of MALT were identified. These cases were classified as DLBCL-NOS. In addition to the DLBCL-NOS and MALTtype lymphomas of thyroid, we encountered three other types of lymphoma primary to the thyroid gland, including follicle centre lymphoma (6\%), T-cell anaplastic large cell lymphoma $(2 \%)$ and peripheral T-cell lymphoma $(2 \%)$. The percentage of follicle lymphomas is significantly lower than in some earlier series, but many MALT-type lymphomas may have been previously diagnosed as follicle centre lymphomas. ${ }^{29,30}$ Since most of our cases $(85 \%)$ were diffuse large B-cell lymphomas, we focused our analysis on this category with the aim to ascertain potential differences in clinical behaviour of DLBCL-NOS and high-grade MALT-type lymphoma. We found that the overall 5-year survivals differed significantly between these two groups ( $75 \%$ vs. $25 \%$ ). The histological subtype and clinical stage were associated with survival on univariate analysis $(P=0.005$ and $P<0.001$, respectively). Given the close relationship between the subtype and clinical stage, the survival advantage of DLBCL-NOS was likely to be stage related (65\% of DLBCL-NOS were stage $\mathrm{I}_{\mathrm{E}}$ compared to $20 \%$ of high-grade MALT-type lymphomas).

It is difficult to place the results of our study in the context of previous studies because of different classifications and criteria for diagnosis. 4,5,7,12,15,17,29 From a histological standpoint, we demonstrated that there are high-grade MALT-type lymphomas, which are distinct from DLBCL-NOS, based on the presence of high-grade LELs or presence of low-grade MALT-type lymphoma in the background. From a clinical standpoint, a general conclusion can be made from the current and previous studies that clinical stage is very important in predicting survival. ${ }^{3-5,7,16,19}$ It appears that even stage $\Pi_{\mathrm{E}}$ disease is significantly worse than disease limited to the thyroid. ${ }^{4,5,7,16}$
There is less consensus about the prognostic value of histological grade. Only two other studies incorporating the MALT-type category of PTL published survival data. $^{18,19}$ Pedersen reported that histological grade was not a statistically significant factor in survival, although high stage ( $\left.\mathrm{III}_{\mathrm{E}}-\mathrm{IV}\right)$ was significant. ${ }^{19}$ In contrast, Laing et al. found that the presence of histopathological features of MALT was a statistically significant factor in patient survival. ${ }^{18}$ They also found that among high-grade lymphomas, presence of a MALT component was a favourable prognostic factor. The authors did not directly assess the effect of lowgrade histology since they combined both high- and low-grade grade lymphomas into their MALT category. Interestingly, in contrast to most series, they found that stage was not a significant prognostic factor. In the older literature, major studies from Aozosa et al. ${ }^{3}$ and Compagno et al. ${ }^{5}$ found that histological grade was a signficant factor in survival. Of note, Compagno specifically stated that patients with 'plasmacytomas' were significantly more likely to be disease-free as compared to all other types. ${ }^{5}$ It is likely that these cases of 'plasmacytomas' were low-grade MALT-type lymphomas with plasmacytoid differentiation. ${ }^{31}$ Clinical follow-up showed that all three patients in our study with low-grade MALT-type lymphoma were alive without disease, suggesting a favourable clinical behaviour. Similar results were reported in the study of Hyjek et al. in which none of three patients with follow-up died of lymphoma. ${ }^{6}$ The small number of cases in our series was not sufficient for meaningful analysis. Since there are very few reported cases of low-grade MALT-type lymphoma of thyroid, larger long-term follow-up studies are required. However, we suspect that localized lowgrade MALT-type lymphomas of thyroid have an excellent prognosis as appears to be the case in other extranodal sites.

Overall, DLBCL-NOS presented in lower stage and showed a significantly longer survival as compared to the high-grade MALT-type lymphomas on univariate analysis. The association between histological subtype of DLBCL and stage was very strong and the shorter survival of HG MALT-type lymphoma is likely stage related. One may speculate that DLBCL-NOS, as a de novo neoplasm, is likely to come to attention sooner than a slower growing MALT-type lymphoma starting as a low-grade lymphoma and undergoing subsequent transformation to a high-grade tumour. Consequently, DLBCL-NOS might be a more easily palpable, targeted mass that lends itself to needle biopsy. Perhaps most high-grade MALT-type lymphomas arise from lowgrade MALT-type lymphoma pre-existing for a long time (subclinically) that becomes higher stage prior to 
transforming to a large cell lymphoma. Although we did not note this feature in our cases, Hyjek et al. reported that eight of 10 of their high-grade primary thyroid lymphomas contained centrocyte-like cells. ${ }^{6}$ In addition, d'Amore and colleagues noted in their series of 463 extranodal lymphomas that disseminated disease was significantly associated with a low-grade histology, suggesting that low-grade extranodal lymphomas may indeed become higher stage prior to transformation. ${ }^{32}$

Assignment of an individual case into this category appeared to be affected by the specimen type because all high-grade MALT-type lymphomas were diagnosed on excisional specimens. In order to eliminate the influence of the type of the specimen on our findings we performed a separate analysis after exclusion of all needle biopsy specimens. This survival analysis limited to excisional biopsies and thyroidectomy specimens confirmed the significance of both the subtype (DLBCL-NOS vs. HG MALT-type lymphoma) and the clinical stage (stage $\mathrm{I}_{\mathrm{E}}$ vs. stages $\mathrm{II}_{\mathrm{E}}-\mathrm{IV}$ ) for survival.

In summary, we report a retrospective study of primary thyroid lymphomas that have been clinically, histopathologically and immunophenotypically characterized and reclassified according to the presence or absence of features of MALT. These lymphomas occur most often in older women. DLBCL was by far the most common type of lymphoma encountered at this site. Low-grade MALT-type lymphoma is relatively uncommon and in our limited follow-up appears to have a good prognosis. High-grade MALT-type lymphomas could frequently be identified based on presence of a low-grade component or high-grade LELs. Among DLBCL, subtype and clinical stage were the only statistically significant prognostic factors on univariate analysis. The presence of MALT features in DLBCL was associated with higher stage at presentation, a finding that remains to be explained as more knowledge is gained about the pathogenesis of this lymphoma. At issue is whether DLBCL is a single entity. Recently, Chan et al. found evidence of trisomy 12 in DLBCL-NOS more often than in HG MALT-type lymphoma supporting a true difference between these lymphomas at the molecular level. ${ }^{33}$ In a recent report, Hoeve and collegues found a higher incidence of trisomies 12 and 18 in HG MALTtype lymphomas as opposed to large cell lymphoma of the stomach ( $64 \%$ vs. $20 \%$, respectively). ${ }^{34}$ Although somewhat contrary to the study by Chan et al. their findings also support the contention that HG MALT-type lymphomas may be different than de novo large cell lymphomas. Our data support the concept that DLBCL of the thyroid is heterogeneous, with high-grade MALTtype lymphoma, as we have defined it, being separable from DLBCL-NOS. Additional studies are required to further investigate the genetic abberations associated with high-grade MALT-type lymphomas and DLBCLNOS to resolve this issue.

\section{References}

1. Gospodarowicz MK, Sutcliffe SB. The extranodal lymphomas. Sem. Rad. Oncol. 1995; 5; 281-300.

2. Freeman C, Berg JW, Cutler SJ. Occurrence and prognosis of extranodal lymphomas. Cancer 1972; 29; 252-260.

3. Aozasa K, Ueda T, Katagiri S, Matsuzuka F, Kuma K, Yonezawa T. Immunologic and immunohistologic analysis of 27 cases with thyroid lymphomas. Cancer 1987; 60; 969-973.

4. Burke JS, Butler JJ, Fuller LM. Malignant lymphomas of the thyroid: a clinical pathologic study of 35 patients including ultrastructural observations. Cancer 1977; 39; 1587-1602.

5. Compagno J, Oertel JE. Malignant lymphoma and other lymphoproliferative disorders of the thyroid gland. A clinicopathologic study of 245 cases. Am. J. Clin. Pathol. 1980; 74; 111.

6. Hyjek E, Isaacson PG. Primary B cell lymphoma of the thyroid and its relationship to Hashimoto's thyroiditis. Hum. Pathol. 1988; 19; 1315-1326.

7. Makepeace AR, Fermont DC, Bennett MH. Non-Hodgkin's lymphoma of the thyroid. Clin. Radiol. 1987; 38; 277-281.

8. Isaacson PG, Norton AJ. Malignant lymphoma of the thyroid gland. In: Extranodal Lymphomas. Edinburgh: Churchill Livingstone, 1994: 103-115.

9. Aozasa K, Inoue A, Yoshimura H et al. Intermediate lymphocytic lymphoma of the thyroid. Cancer 1986; 57; 1762-1767.

10. Chak L, Hoppe R, Burke JS, Kaplan HS. Non-Hodgkin's lymphoma presenting as thyroid enlargement. Cancer 1981; 48; 27122716.

11. Faure P, Chittal S, Woodman-Memetau F et al. Diagnostic features of primary malignant lymphomas of the thyroid with monoclonal antibodies. Cancer 1988; 61; 1852-1861.

12. Hamburger JI, Miller JM, Kini SR. Lymphoma of the thyroid. Ann. Int. Med. 1983; 99; 685-693.

13. Heimann R, Vannineuse A, De Sloover C, Dor P. Malignant lymphomas and undifferentiated carcinomas of the thyroid: a clinicopathological review in the light of the Kiel classification for malignant lymphomas. Histopathology 1978; 2; 201-213.

14. Katsuyuki A, Akifumi I, Kazuo T, Akira M, Fumio M, Kanji K. Malignant lymphoma of the thyroid gland. Analysis of 79 patients on histologic prognostic factors. Cancer 1986; 58; 100-104.

15. Maurer R, Taylor CR, Terry R, Lukes RJ. Non-Hodgkin's lymphomas of the thyroid. Virch. A Path. Anat. 1979; 383; 293-317.

16. Mizukami Y, Michigishi T, Nonomura A et al. Primary lymphoma of the thyroid: a clinical, histological and immunohistochemical study of 20 cases. Histopathology 1990; 17; 201-209.

17. Rasbach DA, Mondschein MS, Harris NL, Kaufman DS, Wang CA. Malignant lymphoma of the thyroid gland: a clinical and pathologic study of twenty cases. Surgery 1985; 98; 11661170.

18. Laing RW, Hoskin P, Hudson BV et al. The significance of MALT histology in thyroid lymphoma: a review of patients from the BNLI and Royal Marsden Hospital. Clin. Oncol. (R. Coll. Radiologists) 1994; 6; 300-304.

19. Pedersen RK, Pedersen NT. Primary non-Hodgkin's lymphoma of the thyroid gland: a population based study. Histopathology 1996; $28 ; 25-32$. 
20. Rudders RA, De Ross ME, Lellis RA. Primary extranodal lymphoma: response to treatment and factors influencing prognosis. Cancer 1978; 42; 406-416.

21. Musshoff K. Klinische Stadieneinteilung der nicht-Hodgkin Lymphome. Strahlentherapie 1977; 153; 218-221.

22. Rosenberg SA. Validity of the Ann Arbor staging classification for the non-Hodgkin lymphomas. Cancer Treat. Rev. 1977; 61; 10231087.

23. Chan JK, Banks PM, Cleary ML et al. A revised EuropeanAmerican classification of lymphoid neoplasms. Am. J. Clin. Pathol. 1995; 103; 543-560.

24. Bouzourene H, Haefliger T, Delacretaz F, Saraga E. The role of Helicobacter pylori in primary gastric MALT lymphoma. Histopathology 1999; 34; 118-123.

25. Cogliatti SB, Schmid U, Schumacher U et al. Primary B-cell gastric lymphoma: a clinicopathological study of 145 patients. Gastroenterology 1991; 101; 1159-1170.

26. Hsi ED, Eisbruch A, Greenson JK, Singleton TP, Ross CW, Schnitzer B. Classification of primary gastric lymphomas according to histologic features. Am. J. Surg. Pathol. 1998; 22; 17-27.

27. Nakamura S, Akazava K, Yao T, Tsuneyoshi M. Primary gastric lymphoma. A clinicopathological study of 233 cases with special reference to evaluation of the MIB-1 index. Cancer 1995; 76; 1313-1324.
28. de Jong D, Boot H, van Heerde P, Hart GA, Taal BG. Histological grading in gastric lymphoma: pretreatment criteria and clinical relevance. Gastroenterology 1997; 112; 1466-1474.

29. Anscombe AM, Wright DH. Primary malignant lymphoma of the thyroid - a tumour of mucosa-associated lymphoid tissue: review of seventy-six cases. Histopathology 1985; 9; 81-97.

30. Isaacson PG, Androulakis-Papachristou A, Diss TC, Pan L, Wright DH. Follicular colonization in thyroid lymphoma. Am. J. Pathol. 1992; 141; 43-52.

31. Hussong JW, Perkins SL, Schnitzer B, Hargreaves H, Frizzera G. Extramedullary plasmacytoma. A form of marginal zone cell lymphoma? Am. J. Clin. Pathol. 1999; 111; 111-119.

32. D'Amore F, Christensen BE, Brincker H et al. Clinicopathological features and prognostic factors in extranodal non-Hodgkin lymphomas. Eur. J. Cancer 1991; 27; 1201-1208.

33. Chan WY, Wong N, Chan ABW, Chow JHS, Lee JCK. Consistent copy number gain in chromosome 12 in primary diffuse large cell lymphomas of stomach. Am. J. Pathol. 1998; 152; 11-16.

34. Hoeve MA, Gisbertz IA, Shouten HC et al. Gastric low-grade MALT lymphoma, high-grade MALT lymphoma and diffuse large B-cell lymphoma show different frequences of trisomy. Leukemia 1999; 13; 799-807. 